Natural and Applied Sciences International Journal (NASIJ) eISSN: 2788-4619 (online)

https://doi.org/10.47264/idea.nasij/2.1.2

Vol. 2, No. 1, (January-December 2021), 12-25

https://www.ideapublishers.org/index.php/nasij

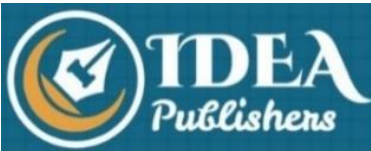

Research Article

\title{
GNSS and GIS based android integration of mobile based virtual guide application ExpLahore for walled city Lahore, Pakistan
}

Aaysha Rahim*1 ${ }^{*}$ Najam Abbas Naqvi ${ }^{1-2}$

1. Department of GNSS, Institute of Space Technology, Islamabad, Pakistan.

2. Space Education and GNSS Lab, National Center of GIS and Space Application, Institute of Space Technology, Islamabad, Pakistan.

* Corresponding Author Email: aaysha.rahim.ar@gmail.com

Published Online: September 15, 2021

\begin{abstract}
The expansion of technology by utilizing Global Navigation Satellite Systems (GNSS) integrated with Geographic Information System (GIS) has made life much easier and handy. Global interactions have given birth to tourism and intra-culture programs. Many foreigners as well as local tourists prefer to explore the sites on their own instead of a guide, this is quite adventurous but can be tedious too and brings along a lot of security risks. Information and precise location of 14 place groups of Lahore city, as well as precise route to them is also a feature of the application. The research and product are unique in such a way that currently no other source is using GNSS, GIS and Android integrated services. Secondly, the coordinates used to display precise location and route have been extracted through Open Street Map (OSM). Feature of geotagging pictures includes satellite count as well as altitude.
\end{abstract}

Keywords: Global Navigation Satellite Systems (GNSS), Geographic Information System (GIS), Global Positioning Service (GPS), Geo tagging, Android, Tourism.

\section{How to Cite:}

Rahim, A. \& Naqvi, N. A. (2021). GNSS and GIS based android integration of mobile based virtual guide application ExpLahore for walled city Lahore, Pakistan. Natural \& Applied Sciences International Journal (NASIJ), 2(1), 12-25. https://doi.org/10.47264/idea.nasij/2.1.2

\section{Publisher's Note:}

IDEA PUBLISHERS (IDEA Journals Group) stands neutral regarding jurisdictional claims in the published maps and institutional affiliations.

Copyright: ( 2021 The Author(s), published by IDEA PUBLISHERS (IDEA Journals Group)

Licensing: This is an Open Access article published under the Creative Commons AttributionNonCommercial 4.0 International License (http://creativecommons.org/licenses/by-nc/4.0/) 


\section{Introduction}

The history of navigation is as old as human civilization. People navigate for different reasons. Improving and developing accurate methods for navigation has been a vital issue in world history when people used primitive charts, observations of the Sun and Stars, celestial navigation, nautical charts, cross-staff, astrolabe and quadrant, sextant, chip-log, chronometer, ultimately entering the $20^{\text {th }}$ Century and moving towards radio beacons, radars, the gyroscopic compass and after several experiments coming up with development of revolutionary Global Positioning System (GPS), being the first Global Navigation System (GNSS), as discussed by Chang and Lee (2015). The country is rich in heritage, facts and figures for archaeologists, historians, artists, teachers and anthropologists due to all these attributes, an exponential and speedy growth from half Million foreigners in 2015 to two Million tourist arrivals in 2019, according to world tourism monitoring agencies. Whereas, stated by diplomat magazine report on Pakistan (April, 2020), domestic tourism created a benchmark of forty million in 2019.

The capital of Punjab province, Lahore, is the second largest city of Pakistan. It lies in the upper Indus plain on River Ravi. A most surrounded the old city, 13 gates, on a circular rampart, provide access to the old city. Remarkable structures include Wazir Khan Mosque, Lahore Fort, the largest mosque of the world; Badshahi Mosque, Shahdara gardens, Shalimar gardens. Collectively Shalimar Gardens and Lahore Fort were designated as UNESCO World Heritage site in 1981. Having such big tourism industry of country, it is tried to integrate GNSS with GIS and Android technology to help tourists enjoy monuments. This research work has been done to create a handy android tourist guide for old city, Lahore, and to help tourists enjoy the richness of the sights. The application provides precise location and is convenient to use by users of all fields. The key technology used is Mobile Database Technology, Mobile Positioning Technology, and Wireless Network Technology. GIS applications are Super Map, Location-based Service and Mobile Video GIS System. In conclusion, Android-based platform-based GIS application development makes full use of the Android platform's advantage and source characteristics. When improving the system interactive and user experience, it also reduces the cost of development and the universal threshold for universal application. This paper presents an investigation of ongoing research GIS used on Android embedded OS. As elaborated by Ge et al. (2013), on relevant technical background that developing GIS needed in the Android development platform.

This paper discusses about GNSS-GIS-Android Integration for Development of Mobile Based Virtual Guide Application for "walled city, Lahore, Pakistan", which comprises of Integration of GNSS with GIS and Android, Precise Positioning by extracting coordinates and implementing, development of a functional application for the purpose and Availability of application to users. The main aim of the proposed work is to build up an android application named "ExpLahore", that incorporates GNSS with GIS and Android to allow tourists to visit the monuments and shrines of the UN declared world heritage site, "walled city, Lahore" or "andaroon-e-Lahore", on their own, without any guide primarily. Permitting users to enjoy the magnificence and richness of the place in their own comfort zone and solitude.

\section{Literature review}

Technological advances enable progress in tracking tourists. The technological and procedural complexities of electronic tourist surveillance that have been stated in the literature are addressed in operational document by Hardy et al. (2017), direct observation, survey and 
interview-based procedures, and digital tracking are the three main monitoring strategies. According to the system, sensitive strategies that consider the digital infrastructure, cultural contexts, and legislative landscape of research regions, as well as issues like hiring and travel streams, are more likely to establish suitable and appealing technological alternatives for tourist monitoring. The project lessons and a systematic model of study design are discussed in this paper in order to encourage ongoing methodological growth in this growing area of science. This data will aid location management companies in detecting potentially dangerous travel patterns, such as those travelling close to midnight or at high velocities. GPS data with finer resolution can be used. Destinations and attractions will determine how long people spend, what services they need, and where more infrastructure is required. If collected longitudinally, this type of information may one day enable destinations to evaluate effectiveness of marketing strategies. Future study must adapt to the rapidly evolving technology landscape while considering the gradually portable and quickly varying tourism industry, including rapidly changing user perceptions and behaviors towards smartphone and app use. The feasibility of future tourist monitoring research can be determined by how these issues are handled.

Just Quick is an android OS application that provides particulars of a specific city's surrounding services such as ATMs, banks, cafes, hospitals, shops etc. It also includes a connection from the customer's current position to the location of the particular service. This Android program by Tiwari et al. (2016) provides a service to shop online. Service information offered by any person or entity and shown to users who wish to use it. Registered users permission are also granted to insert a new entity into our database and to be able to change a particular field at regular intervals. Next goal would be to provide a forum for the customer to connect with the service provider so they can negotiate and get more benefits. Users will also be provided with a feedback form to provide suggestions and problems they face. Then it will be striven to incorporate it and make it user friendly. Implementing a review option is also under consideration for a given service provider so that it can be reviewed after using a particular service user.

With the progress of technology, the numerous resources and applications take on the role of the guide. The growth in cell phone use has made it easier to provide 'on the go' visitors with various apps. In this design, Fatima et al. (2016) developed an android-based smartphone application which travelers will use as a guide. The primary purpose of this software is to detect and provide specific information about a memorial or a famous location based on a photo that the user has taken or uploaded. This is accomplished through the use of open-cv for the identification of pictures. The information associated with that monument is then displayed. The details can be found in JSON database. This will also be able to point the location of the landmark on the map. Implementing and using the new app would substitute the existing guides with 'electronic guides.' By using app while traveling would enhance the experience so travelers would not have to deal with the hassle of employing a specialist for each location they explore. Proposed software will recognize a memorial or a well-known location based on a photograph taken or uploaded. This application is especially useful for visitors, who first visit any location. This will encourage them to learn more about every place they visit, and the past associated with that place. Providing info about the nearby attractions can also be beneficial to people.

The goal of the Travel Portal effort by Maryam et al. (2016), is to create sophisticated webenabled applications that are tailored to specific customer demands; turnkey apps for travel agents and intermediaries, airlines, hotels, and transportation companies. The framework is made up of the IoS, GPS, Google Maps API, and Google Places API. The data is being read 
from the Google servers right now. Depending on the outcomes the performance of the proposed method is perfect and provides the tourist and travel management agencies with the necessary information. This feature allows the user to learn the path from their present place to their desired destination, including the user's current location using GPS technology as well as looking for certain places around the globe.

Computing through portable technology offers access to maximum Internet users and send knowledge to their devices directly. The program by Tobing (2015) implements Google Map Program Interface (API) to provide users with location-based service. In addition, using the cloud service, the data used for the mobile application is retrieved from the server. The mobile application proposed for tourism is composed of three components. The first part is the application's back-end part. Next comes the front-end portion built to be Samosir's outlet. Web service as a middleware application for sharing information between the front-end and backend components is the last component. In this work, the author developed and created a smartphone application for Android-based tourism. The application displays a message of communication about Samosir regency tourism information is wrapped in JSON format. The front-end program, Samosir, cited the taxonomy of mobile device tourism as the design basis for the key functions. One can bring the mobile app into three out of seven categories. For future projects, the usability of the application and the consumer experience brought to the tourists have to be assessed.

Saranya and Nithya (2015) discussed direction to blind people using an Android Phone with voice navigated GPS has been discussed. This program is a creative and cost-effective system of guides for the blind. Creating a lightweight portable navigation device, the system incorporates wireless communication technology, route planning, and sensors technology. Using GPS, the map is obtained from the given source and destination. The person starts walking toward the destination from his / her source. Each and every turn is then indicated as the order spoken. Even the indication of the wrong direction is rendered by GPS use. This GPS offers information on position and time in all weather conditions, everywhere on Earth. The machine can be called a semi-autonomous unit. This offers global navigation maximum flexibility but also relies on the user's navigation skills.

Tourist demand for reinvigoration is growing by means of information technology and business. Development of a system for recommending tourist spots, the biggest obstacle is the characterization of tourist places Whose traits dynamically change with patterns, events, season, And time of day. Approach used by Oku et al. (2014) supports vector of one class Computer (OC-SVM) for the identification of regions of severe activity near goal points, based on images and tweets explicitly, is geotagged. The method takes unknown geotagged tweets from regions of activity and maps them to target spots. Additionally, the approach extracts characteristics of tourist destinations from the marked tweets.

Considering the growing demand for mobile devices, this paper focuses on identifying and incorporating location-based services to assist with everyday tasks. With development, a new ability to geotag images has been observed in the last decade, using two different devices: a GPS receiver and a camera. Such devices are connected to each device by the time and date settings, and an external application was then used to synchronize them. Sahu and Chakraborty (2013) has been working on developing an image geotagging program for Android devices running version 2.2 or above. A comparison is also drawn on the basis of geo-spatial precision Information between the android phone integrated native camera geotagging. The main aim 
was to draw a distinction between the native camera's GPS information and a self-configured Position Manager (LM). With this, it is concluded that new applications can be designed to deliver services as the public requires. In addition, the proposed framework may be changed to achieve a better trade-off between power and accuracy for later studies and may be applied to more user-friendly systems.

Kuzma (2012) explores the rates of geocoding photos of children's photographs and addresses issues of privacy and safety that can impact them. In this article, from the initial findings the number of children's photographs has been counted manually. Often measured were those images of children with an average age of less than 18 years, even though this was an approximation at times. Photographs of groups of individuals were identified as long as at least one child from the class was included. The goal of this article was to examine a range of geocoded children's imagery and show concern as well as potential solutions to the issues. To begin, the researchers found a small number of photographs of children on Flickr that included geolocation data for specific high-income US postal areas. Since internet visitors will be able to determine the precise place where the children reside, this outcome may have a negative impact on their well-being. Any of these issues can be solved using a multifaceted solution. Finally, since protection must be a top priority, the government must specifically warn parents and individuals who upload photographs to public Web pages of the possible benefits and drawbacks of geolocation content.

This work by Cheng et al. (2010) presents the findings of a mobile app travel study and a completed travel agent program linking GPS on Android platform with Google Map. The creative program lets people schedule their own travels and get exclusive travel facilities on their own. GPS is now used, assisted by mobile devices, to navigate while driving. This work presents the findings of a mobile app travel study and a completed travel agent program linking GPS on Android platform with Google Map. This approach, which incorporates information technology and cultural creativity, is expected to strengthen Aboriginal culture, and entice more people to visit the tribe, in addition to promoting the tourism business. GPS is now used, assisted by mobile devices, to navigate while driving. The project develops a complete system of mobility moving agents with real-time attributes using a combination of the Android smartphone interface and wireless network. Three contributions are made by the program: new technologies can be used to create a creative mobility travel framework. Google Maps and related APIs are being used. When integrating the program, it was discovered that there are already certain limitations with the mobile app that need to be addressed, such as the hardware's memory and battery depletion, as well as the wireless's low signal.

The paper introduces a new approach for geo-tagging automatically, snaps of artificial conditions by identification and surveying fits recurring trends. The approach used by Schindler et al. (2008) exploits the extremely repetitive design of urbanized areas, finding numerous prospectively warped periodic $2 \mathrm{D}$ patterns in a picture and comparing them to a $3 \mathrm{D}$ textured facade database by reasoning about the basic canonical types of each pattern. Several $2 \mathrm{D}$ to $3 \mathrm{D}$ pattern correspondences allow robust camera orientation and position recovery. The writers illustrate this method 's effectiveness in a broad urban environment. Surrounded by tall buildings that display extremely predictable structure, the approach works better.

\section{Methodology}

Android smart devices are efficient enough as they have all the tools assembled in themselves 
that are vital for operating GNSS signals, positively. The devices provide the opportunity to operate GNSS for Precise Positioning and Mapping services through different Application Programming Interface (API's).

This research is based on design and development of an android application considering "walled city, Lahore, Pakistan". The application will help tourist geotag their information. This application provides precise position through GNSS, the coordinates have been refined using ArcGIS and QGIS and placed in application using Android Studio and Adobe Illustrator. GIS allowed creating interactive queries, analyzing spatial information and map creation, shape file extraction and precise coordinates than maps we usually use. In travelling world geotagging is a great and trending feature that lets user share their exact position. The application locates user's coordinates (latitude and Longitude), current satellite count, precision, altitude, time and day. The guidance application helps user find the correct possible route to the monuments of walled city, Lahore. Information and precise location of 14 place groups of Lahore city, as well as precise route to them is also a feature of the application.

The GPS is a communication technology. It transmits location and time information to any installed application or software that requires it through radio waves between satellites and the receiver built into the Android device. It's a hardcoded feature. It is not necessary to send actual data back into space for the GPS chips to work; instead, the computer must be able to transmit data from at least four or more satellites in orbit that have been designated for the purpose.

\section{Tools and software's}

The tools and techniques play a vital role in development of any software or application, for this application, development has been done on Android Studios 4.2 using Java Language version 13.0.2. Adobe Photoshop CS6 and Adobe Illustrator CS6 along with XML 1.0 have been used to cater the design requirements, basically for logo creation, background layout, image resizing and background removal. SQL Lite databases has been used for storage and displaying of coordinated that have been extracted from Open Street Map using ArcGIS and QGIS tool. This application supports OS API level onwards from Android version 4.4 Kitkat. Out of multiple methodologies for software developments, Agile has been considered for application development. The Interfaces used are:

- JAVA 13.0.2 (back-end language)

- XML 1.0 (front-end language)

- SQL Lite SERVER (for database)

- MS-WORD

- MS-VISIO

- Android based mobile (for mobile application)

\section{System features and operation}

The application is able to perform the following functional features:

\subsection{About}

This is first module "About". This screen previews static data and information including brief history and emphasizing and portraying the real picture of the walled city Lahore (Figure 1). 
Figure 1: The flow chart of GNSS-GIS based android app for about introduction of walled city Lahore. This app has latest information about the history, development and future aspects of the walled city.

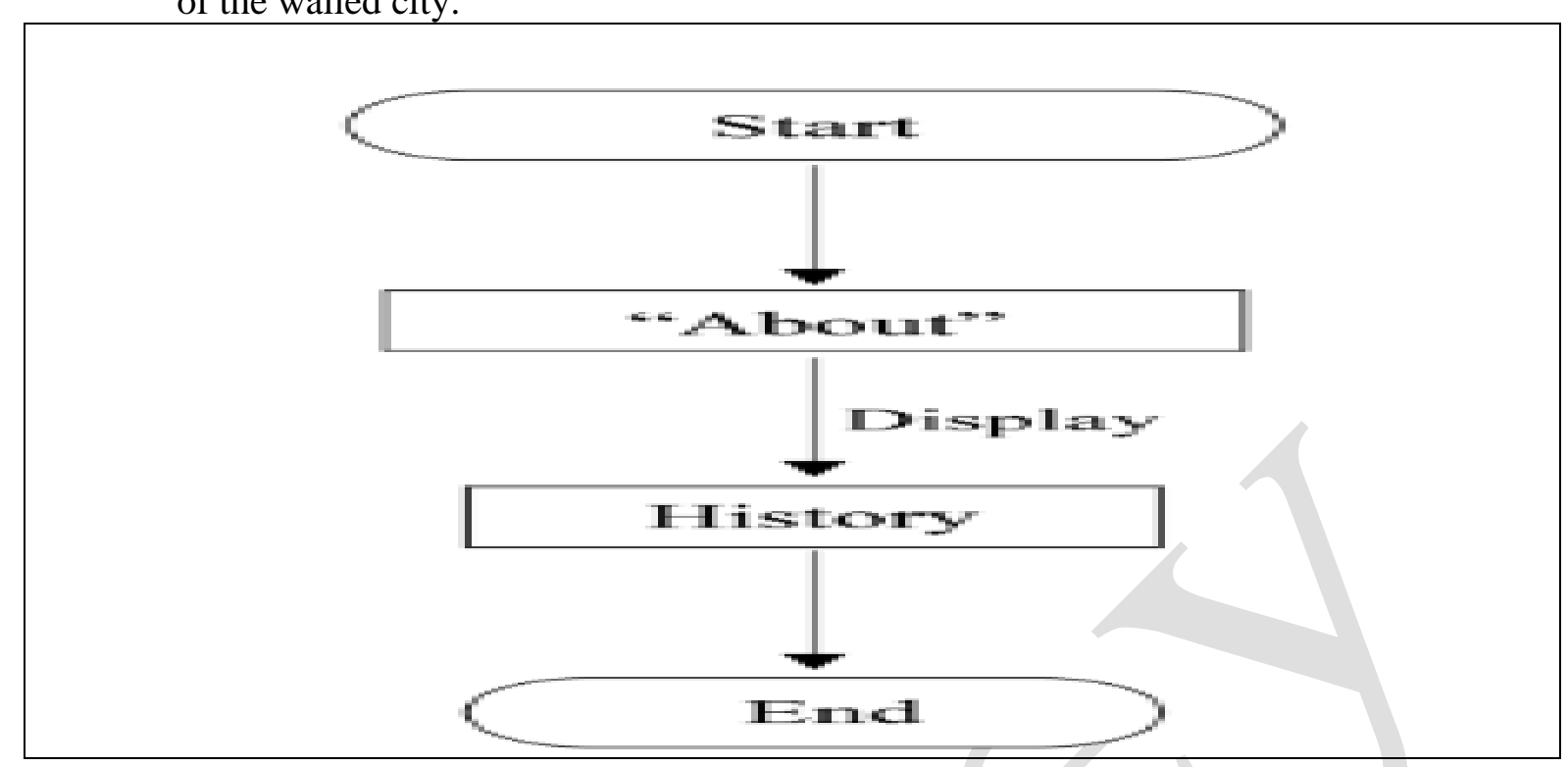

\subsection{Monuments}

The "Monuments" is name given to module that refers to fourteen different architectural sights that are located inside walled city Lahore. These include Badshahi Mosque, Lahore Fort, Minar-e-Pakistan, Wazir Khan Mosque, Lahore Museum, Shahi Hamam, Hazuri Bagh, Data Darbar, Allama Iqbal Tomb, Tomb of Jahangir, Grand Jamia Mosque, Lahore Arts Council, Aiwan e Iqbal, and Akbari Sarai (Figure 2).

Figure 2: The significance of the App from with deep insight having more features extractions about the GNSS-GIS search tool of walled city Lahore guide map.

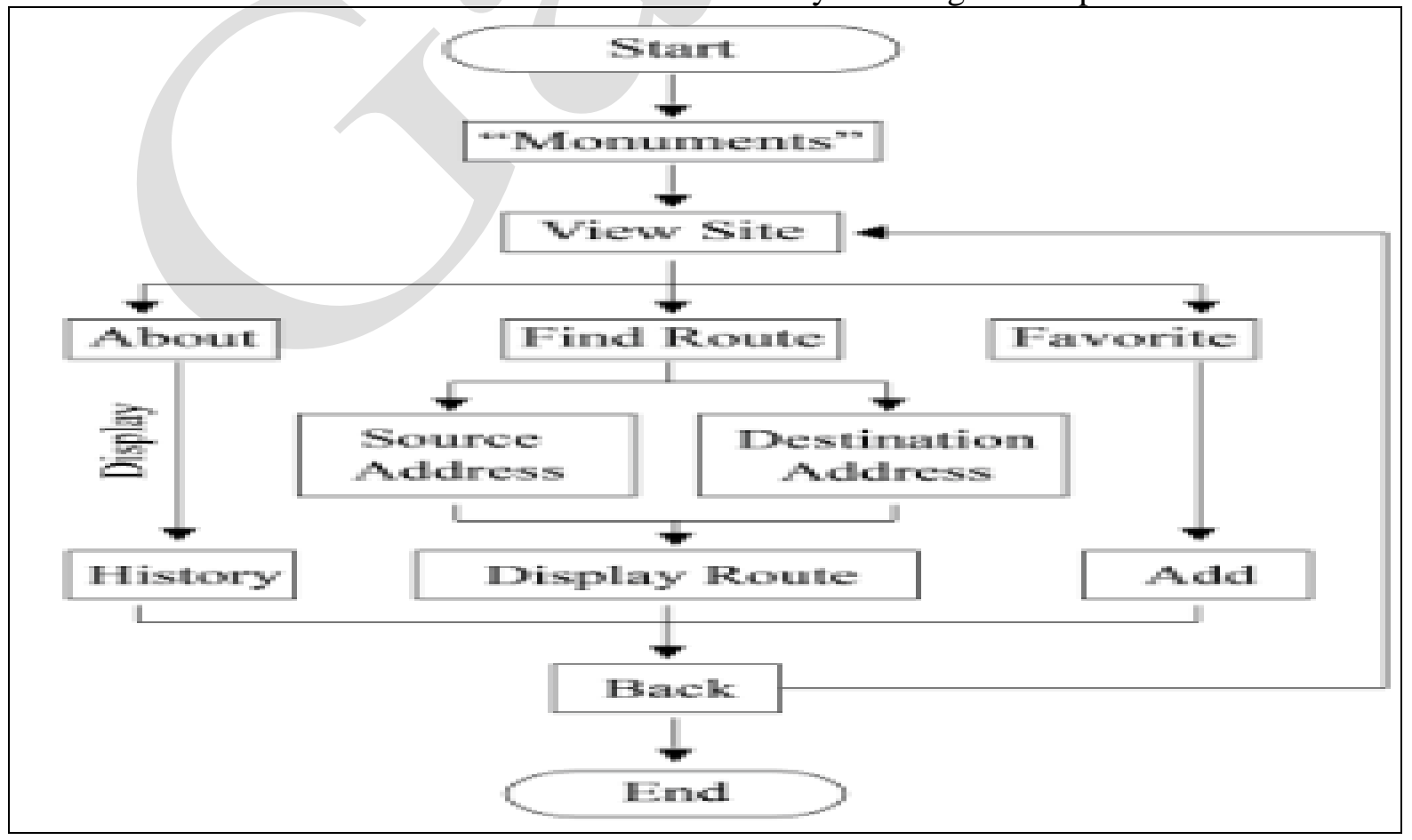


These sights are tourist's attraction from all over the world (Figure 3). This module features are as follow:

- Views detail of each sight including its history and significance

- User can add sight to his favorites for easy access

- User can easily find route to selected sight by pressing the location icon, from his current location.

Figure 3: (a) ExpLahore Monuments module 1, (b) Monuments-display info 1, (c) Monumentsview Monument 1, and (d) Monuments-display route 1

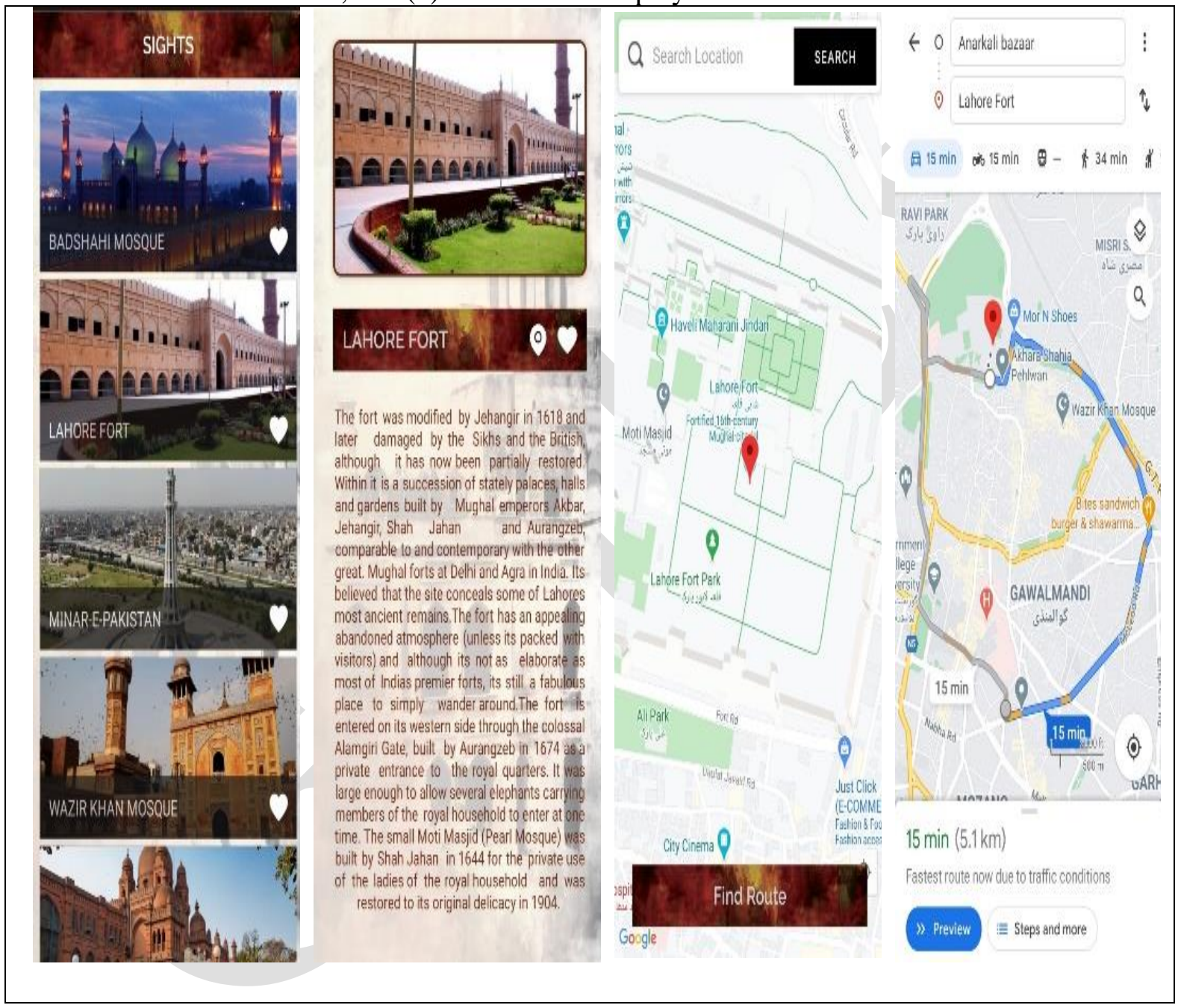

\subsection{Places}

The third module of the application is "Places". It includes fourteen different place categories that includes 1,675 points namely 47 ATMs, 251 Banks, 96 Bus Stops, 39 Clinics, 43 Colleges, 130 Fuel Stations, 182 Hospitals, 84 Hotels, 51 Pharmacies, 230 Worship Places, 32 Police Stations, 239 Restaurants, 140 Schools, 91 Traffic Signals and 20 Universities. These points are not only of walled city, but complete Lahore. These points have been extracted from Open Source Map. On selection of any category a cluster of all points, that have been integrated and 
updated with google maps, appear on screen in form of markers. On pinpointing any marker, the coordinates as well as route finding option appears for the user (Figure 4).

Figure 4: Location based services for different tourist spots using GNSS-GIS for different locations of old walled city of Lahore.

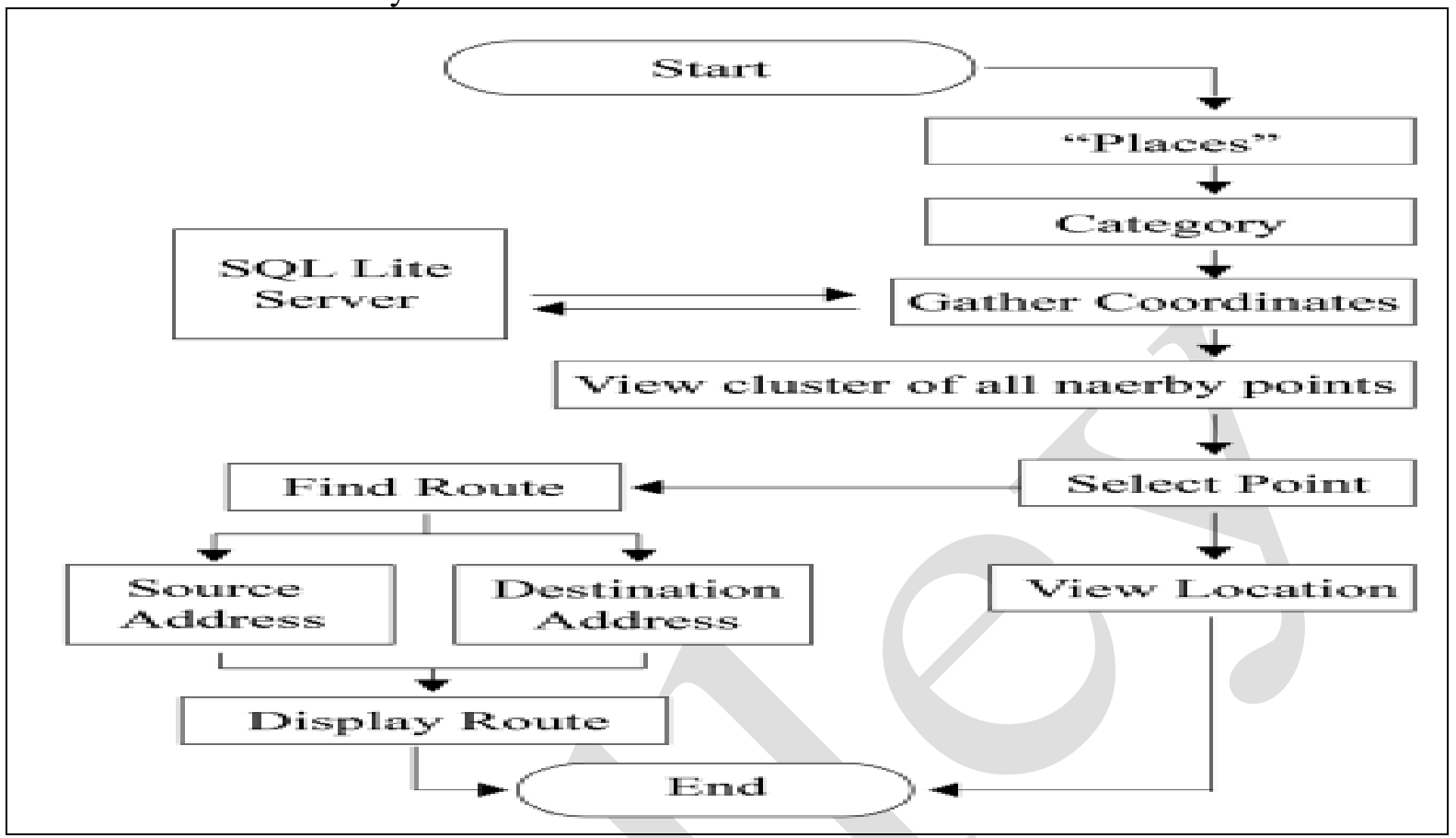

This makes decision for tourists easier, by viewing the nearby points and allowing to choose the place they are looking for, as well as finding route to the required destination (Figure 5). After implementation the module works as shown in figure 5.

Figure 5: (a) Places display screen 1, (b) Places display screen 2, (c) Places category selection, and (d) Places display route to selection

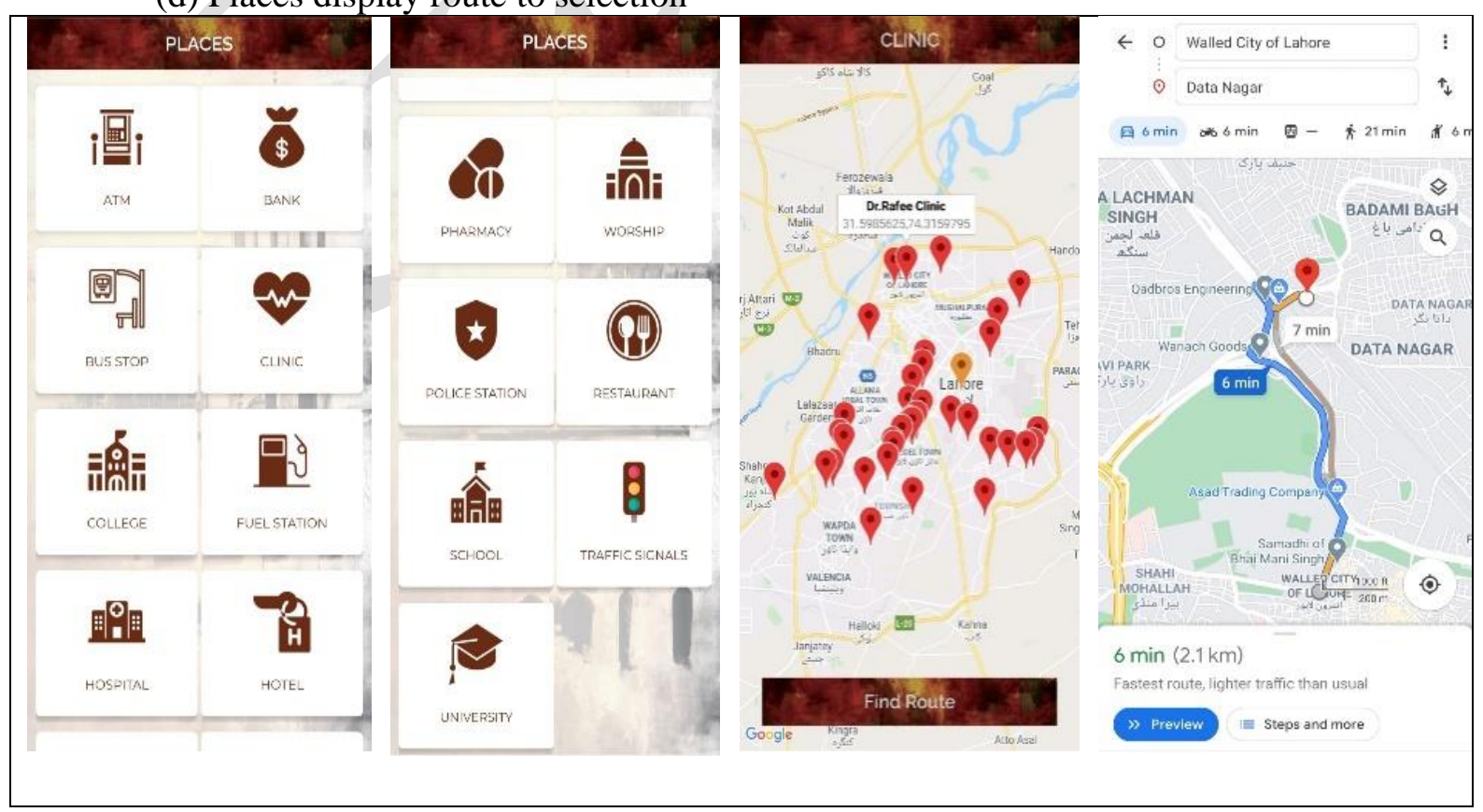




\subsection{Moments}

This is the fourth module of the application. This module allows user to capture images at any time. The captured images view user's location by showing latitude, longitude, location, altitude, precision and satellite count of user at that particular time. This feature allows tourists to remember their tour by displaying exact location of the place (Figure 6).

Figure 6: Integration of GPS and GIS for accuracy of position-based service in the Android app of walled city Lahore

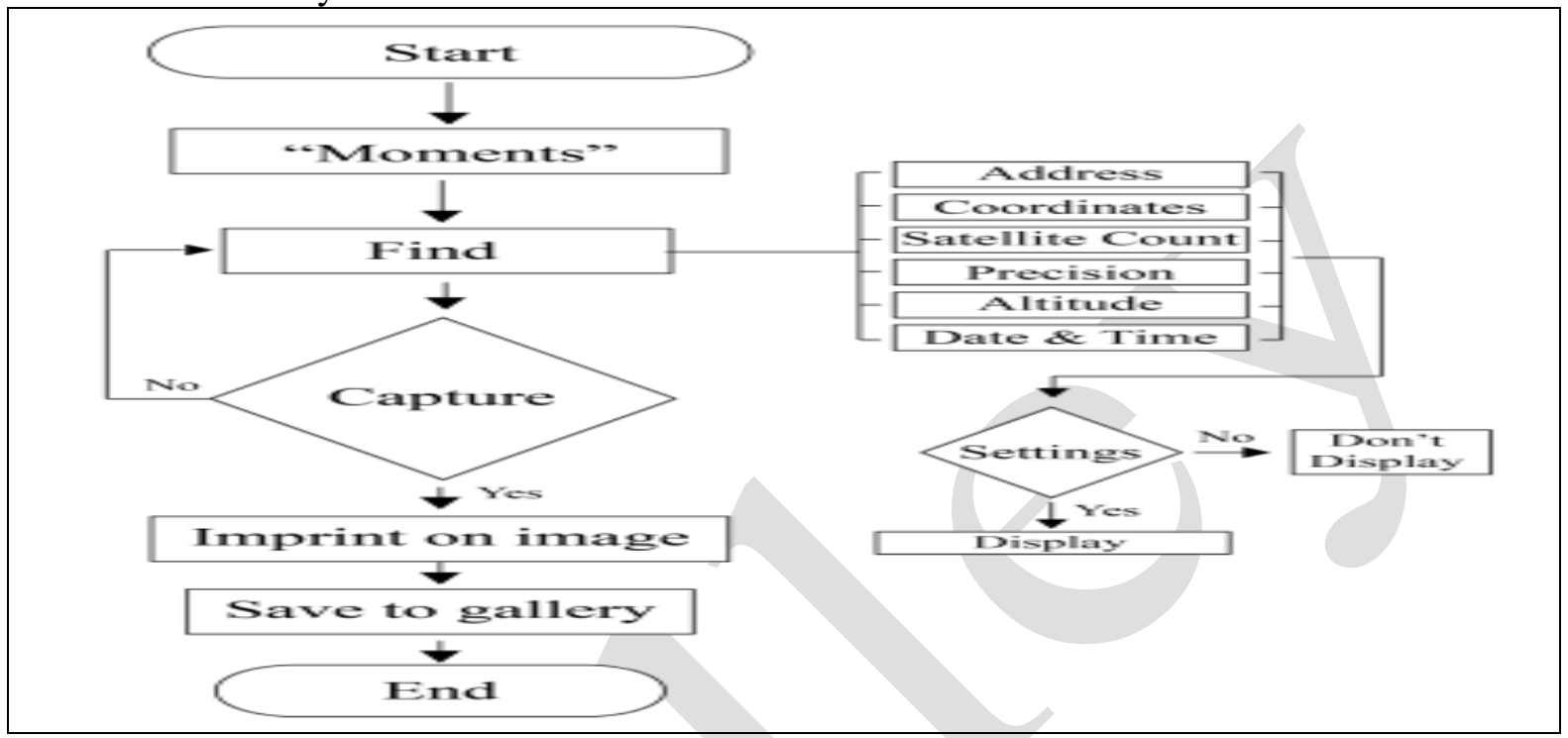

Where, satellite count shows the current degree of GPS satellites which represent current state of GPS engine. Moreover, the precision represents the horizontal accuracy of the location selected, radial, in meters. The altitude shows height, in meters above the WGS 84 reference ellipsoid. If this location has no height, then 0.0 is shown (Figure 7). After Implementation the working of module is shown in figure 7.

Figure 7: (a) Moment's screen main view, (b) moments screen settings, and (c) moments picture shown in gallery

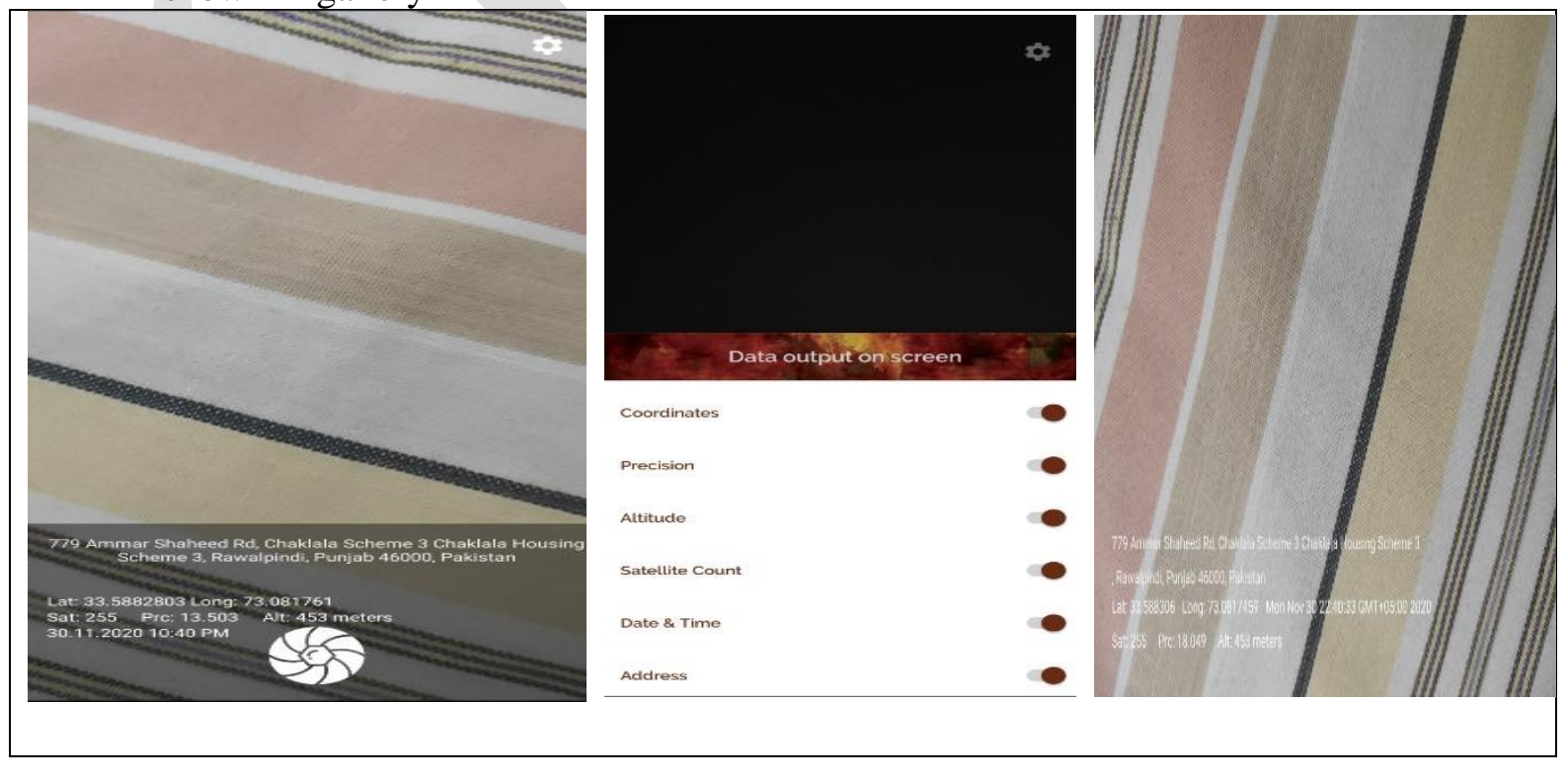




\subsection{Favourites}

This module allows user to view the favourite sights that were marked as favorite in module 1 of the map. This allows easy access to the sight. User can find route of that sight and even unfavorite that sight if needed (Figure 8).

Figure 8: This feature shows the route to the specific place and guide the user to the specific location

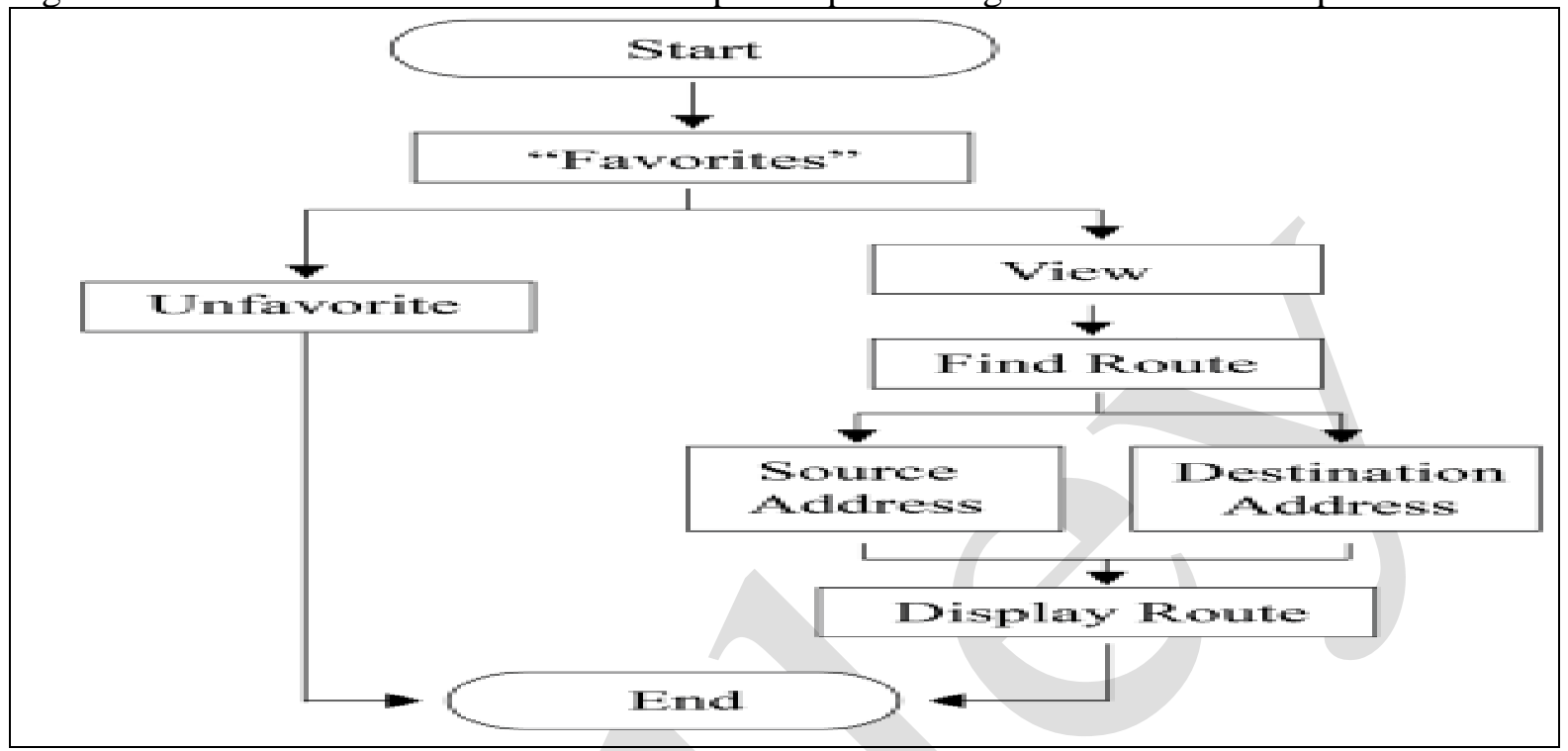

\subsection{Contact us}

This is the sixth and last module of the application that allows user to send any query or contact the developers with reference to the product. User can send email that is only saved in database and can be only viewed and responded back by authorized personals (Figure 9).

Figure 9: The most important part of the GNSS-GIS based android app is to contact the developers or owner of the location for more guidance and knowledge about the place

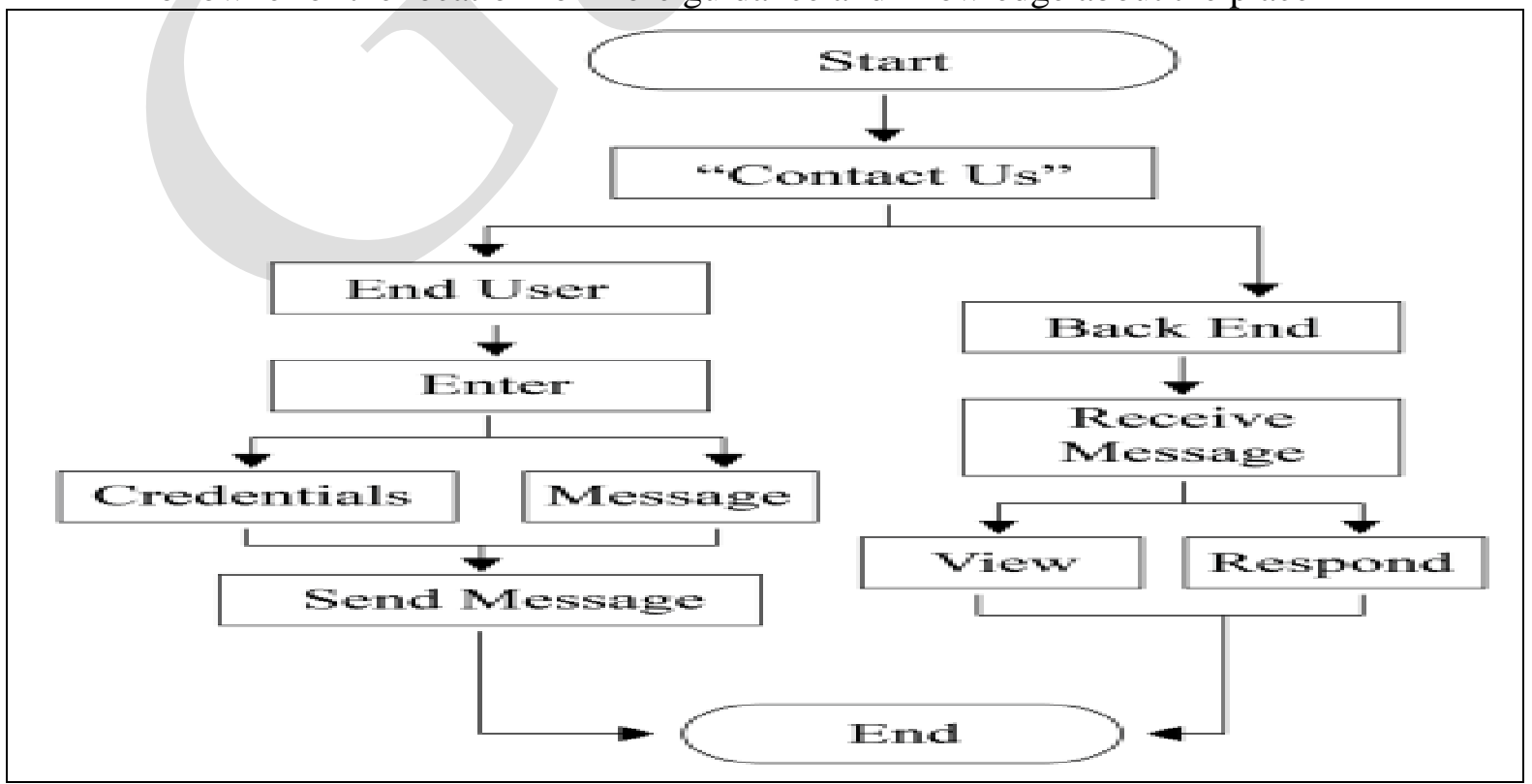




\section{Results}

The application has been widely accepted and liked by users, until now it has 50+ downloads and reviews rate of $4.8 / 5$ based on 6 reviews. The application can be downloaded from the link (https://play.google.com/store/apps/details?id=com.wclapp.wcl). After installation the application occupies $43 \mathrm{MB}$ space on device.

\section{Findings}

In this study authors have studied on design and development of an android application considering "walled City, Lahore, Pakistan". The application will help tourist geotag their information. This application has been developed with the fact to provide precise position through GNSS, the coordinates have been refined using ArcGIS and QGIS and placed in application using Android Studio and Adobe Illustrator. GIS allowed creating interactive queries, analysing spatial information and map creation, shape file extraction and $99 \%$ precise coordinates than maps we use. In travelling world, geotagging is a great and trending feature that allows user to share their exact position. The application will locate user's coordinates (Latitude and Longitude), current satellite count, precision, altitude, time and day. The guidance application helps user find the correct possible route to the monuments of walled City, Lahore.

\section{Conclusion}

This research has developed "expLahore application" to ease tourist experience of walled city, Lahore. it is available to the masses only if they are using android devices, like smart phones, palmtops, tablets etc. All features discussed have been implemented successfully allowing user to search for best options, with precise coordinates and accurate data, which is available to the user at all times.

\subsection{Limitations}

An android device with an active internet connection, having a camera and GPS chip are necessary.

\subsection{Future work}

- Making similar application for Windows and IoS platform.

- Similar duplication of the application for different tourist sights of Pakistan and even worldwide.

- To make and design interactive maps using precise coordinates that could allow users to mark and save their note.

\section{References}

Atunggal, D., Ausi, N. H., Ma'ruf, B., \& Rokhmana, C. A. (2017). Application of Low Cost RTK GPS Module for Precise Geotagging using Smartphone. Jakarta, SN, 89-92. 
Chang, S., \& Lee, Y. T. (2015). A consumer synchronizer for T-DMB receiver based on cooperative communications in emergency alert systems. IEEE Transactions on Consumer Electronics, 61(4), 411-419. https://doi.org/10.1109/TCE.2015.7389794

Cheng, J. S., Hsiang, H. W., \& Wu, W. C. (2010, December). The design of intelligent mobile tourism service system. In 2010 International Computer Symposium (ICS2010) (pp. 813-817). IEEE.

Dar, N. A., \& Khan, A. A. (2013). A system to track android devices: An implementation of lbs, location manager, services and web-services in android. International Journal of Mathematics \& Computing System, 4(1), 49-54.

Fatima, R., Zarrin, I., Qadeer, M. A., \& Umar, M. S. (2016, July). Mobile travel guide using image recognition and GPS/Geo tagging: A smart way to travel. In Thirteenth International Conference on Wireless and Optical Communications Networks (WOCN) (pp. 1-5). IEEE. https://doi.org/10.1109/WOCN.2016.7759893

Ge, J., Wang, F., \& Deng, H. (2013, November). An Investigation on GIS Technology for Android Embedded System. In 6th International Conference on Intelligent Networks and Intelligent Systems (ICINIS) (pp. 312-315). IEEE. https://doi.org/10.1109/ICINIS.2013.87

Hardy, A., Hyslop, S., Booth, K., Robards, B., Aryal, J., Gretzel, U., \& Eccleston, R. (2017). Tracking tourists' travel with smartphone-based GPS technology: A methodological discussion. Information Technology \& Tourism, 17(3), 255-274. https://link.springer.com/article/10.1007/s40558-017-0086-3

Hu, S. Y., Wey, T. S., Lin, M. H., \& Hu, N. T. (2011, December). A simplified design of the embedded e-call system using GPS. In second international conference on innovations in bio-inspired computing and applications (pp. 237-240). IEEE.

Kuzma, J. M. (2012). Children and geotagged images: Quantitative analysis for security risk assessment. International Journal of Electronic Security and Digital Forensics, 4(1), 54-64. https://doi.org/10.1504/IJESDF.2012.045390

Maryam, A., Siddiqui, N., Qadeer, M. A., \& Umar, M. S. (2016, July). Travel management system using GPS \& geo tagging on Android platform. In Thirteenth International Conference on Wireless and Optical Communications Networks (WOCN) (pp. 1-6). IEEE. https://doi.org/10.1109/WOCN.2016.7759019

Oku, K., Ueno, K., \& Hattori, F. (2014, August). Mapping geotagged tweets to tourist spots for recommender systems. In 2014 IIAI 3rd International Conference on Advanced Applied Informatics (pp. 789-794). IEEE.

Sahu, I., \& Chakraborty, I. (2013). Understanding Location Manager in Android and Implementing an Optimal Image Geotagging Application. International Journal of Computer Trends and Technology (IJCTT), 4(6), 1682-1686. http://ijcttjournal.org/archives/ijctt-v4i6p129

Saranya, M., \& Nithya, K. (2015). Campus Navigation and Identifying Current Location through Android Device to Guide Blind People. International Research Journal of Engineering and Technologi (IRJET), 2(8), 1339-1343. https://www.irjet.net/archives/V2/i8/IRJET-V2I8202.pdf

Schindler, G., Krishnamurthy, P., Lublinerman, R., Liu, Y., \& Dellaert, F. (2008, June). Detecting and matching repeated patterns for automatic geo-tagging in urban environments. In IEEE Conference on Computer Vision and Pattern Recognition (pp. 1-7). IEEE. https://doi.org/10.1109/CVPR.2008.4587461

Tiwari, S. K., Varshney, G. K., Qadeer, M. A., \& Umar, M. S. (2016, July). JustQuick: Intelligent LBS using Android with GPS and geo-tagging applications. In 2nd 
International Conference on Applied and Theoretical Computing and Communication Technology (iCATccT) (pp. 820-824). IEEE. https://doi.org/10.1109/ICATCCT.2016.7912113

Tobing, R. D. H. (2015, August). Mobile tourism application for Samosir Regency on Android platform. In International Symposium on Technology Management and Emerging $\begin{array}{llll}\text { Technologies } & \text { (ISTMET) }\end{array}$ https://doi.org/10.1109/ISTMET.2015.7359038

Whipple, J., Arensman, W., \& Boler, M. S. (2009, October). A public safety application of GPS-enabled smartphones and the android operating system. In 2009 IEEE International Conference on Systems, Man and Cybernetics (pp. 2059-2061). IEEE. 